\title{
RESEARCH OF A SPATIAL FLOW OF A LOW-FLOW STAGE OF A SVD-22 CENTRIFUGAL COMPRESSOR BY COMPUTATIONAL FLUID DYNAMICS METHODS USING SUPER-COMPUTER TECHNOLOGIES
}

\author{
Yuri Kozhukhov ${ }^{1, *}$, Serafima Tatchenkova ${ }^{1}$, Sergey Kartashov ${ }^{1}$, Vyacheslav Ivanov ${ }^{1}$, and Evgeniy Nikitin ${ }^{1}$ \\ ${ }^{1}$ Peter the Great St. Petersburg Polytechnic University, 195251, Saint-Petersburg, Russia
}

\begin{abstract}
This paper provides the results of the study of a spatial flow in a low-flow stage of a SVD-22 centrifugal compressor of computational fluid dynamics methods using the Ansys CFX 14.0 software package. Low flow stages are used as the last stages of multistage centrifugal compressors. Such multistage compressors are widely used in boosting compressor stations for natural gas, in chemical industries. The flow features in low-flow stages require independent research. This is due to the fact that the developed techniques for designing centrifugal compressor stages are created for medium-flow and high-flow stages and do not apply to low-flow stages. Generally at manufacturing new centrifugal compressors, it is impossible to make a control measurement of the parameters of the working process inside the flow path elements. Computational fluid dynamics methods are widely used to overcome this difficulties. However verification and validation of CFD methods are necessary for accurate modeling of the workflow. All calculations were conducted on one of the SPbPU clusters. Parameters of one cluster node: AMD Opteron 280 - 2 cores, 8GB RAM. The calculations were conducted using 4 nodes (HP MPI Distributed Parallel startup type) with their full load by parallelizing processes on each node.
\end{abstract}

\section{Introduction}

The object of the study is an intermediate low-flow stage SVD-22, intended for operation in centrifugal compressors of high and ultra-high pressure (injection of natural gas into underground storage, chemical production, etc.). The stage was designed and a natural experiment was carried out for it by the scientific group of prof. L. Ya. Strizhak (Department of Compressor, Vacuum and Refrigeration Engineering (CVRE) SPbSPU) [1-3] The peculiarities of this type of steps are channels of small width, which is why boundary layers at the surfaces of the flow path have a significant effect on the flow and characteristics of the steps, gas leaks and leaks through labyrinth seals. There are known works with simplified modeling of flow in seals and gaps in other software packages, in which the flow is modeled according to predetermined empirical characteristics, significantly reducing the accuracy of calculations.

\section{Methods}

CFD methods are widely used to calculate turbocompressors [4-7]. Additionally it is necessary to apply methods of calculating the properties of real gases [8-10].

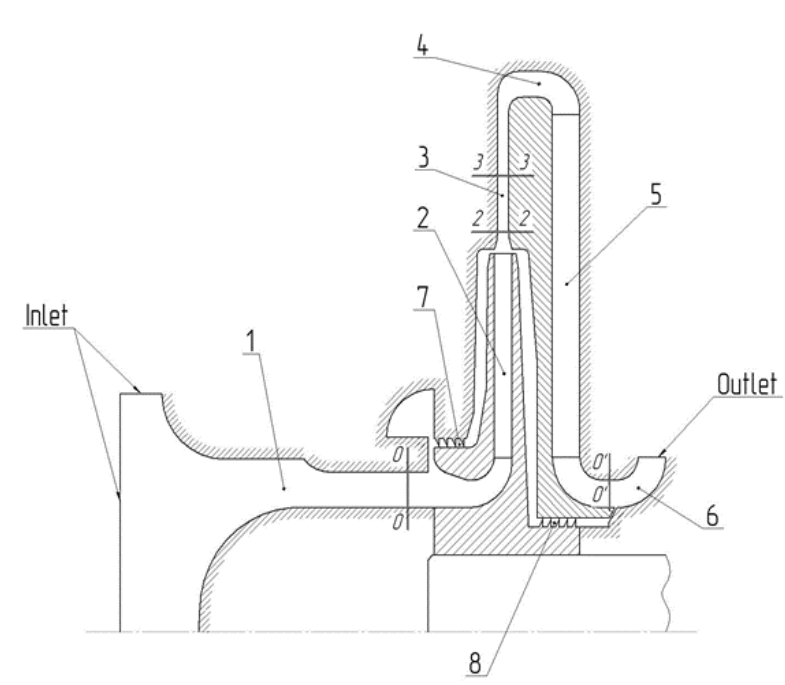

Fig. 1. Sketch of the flow path of the SVD-22 stage in the meridian plane.

In particular, there are studies by CFD methods of low-flow stages of a centrifugal compressor [11-16]. The flow path of the stage, the sketch of which is shown in Fig. 1, consists of: suction nozzle (pos. 1), impeller (pos. 2), vaneless diffuser (pos. 3), swinging elbow (pos. 4), return channel (pos. 5), outlet (pos. 6), labyrinth seal

\footnotetext{
* Corresponding author: kozhukhov_yv@mail.ru
} 
No.1 for the shroud (pos. 7), labyrinth seal No.2 for the shaft (pos. 8).

The aim of this work is to obtain the fluid dynamics characteristics of the low-flow stage SVD-22 by modeling the flow of a viscous gas in the flow path using computational fluid dynamics methods and comparing the obtained characteristics with the results obtained as a result of a full-scale experiment - verification of the calculation data. Evaluation of the obtained calculation results based on the data of a full-scale experiment validation of the calculation data.

Full-scale experimental studies of intermediate lowflow stages were carried out at the stand of a closed circuit of the basic research laboratory of the department of CVRE SPbSPU. In the overwhelming majority of experiments, nitrogen was used as the working medium, providing explosive and fire safety during research, excluding the cases of work on an open stand, where air was used [17].

All experimental studies of the SVD-22 stage were carried out at an impeller peripheral speed U2 $=200 \mathrm{~m} / \mathrm{s}$.

Modes with different inlet pressures were tested: 1 atm, $4 \mathrm{~atm}$ and $10 \mathrm{~atm}$. As mentioned above, the regime at $\mathrm{P}_{\text {in }}=1 \mathrm{~atm}$ was carried out using the working medium air, the modes at $\mathrm{P}_{\text {in }}=4$ atm and $\mathrm{P}_{\text {in }}=10$ atm were carried out using the working medium nitrogen.

On all three modes, 2 different diffusers were tested:

a) Diffuser with a width $\mathrm{b} 3=5.3 \mathrm{~mm}$;

b) Diffuser with a width b3 $=6.8 \mathrm{~mm}$;

The tasks solved in this study are to study the effect on the design characteristics of the stage and the flow structure in its elements: seal;

a) The availability and the absence of the labyrinth

b) Different widths of the vaneless diffuser: b3 $=5.3$ $\mathrm{mm}$ and $\mathrm{b} 3=6.8 \mathrm{~mm}$;

c) Inlet pressure: $P_{\text {in }}=1 \mathrm{~atm}$ and $P_{\text {in }}=10 \mathrm{~atm}$;

d) Working fluid: air with ideal properties (Air Ideal Gas) and nitrogen with real properties.

In this work, 12 different stage characteristics were calculated:

1. Diffuser width b3 $=5.3 \mathrm{~mm}$, the working fluid is "Air Ideal Gas", $P_{\text {in }}=1$ atm, the stage was counted without seals;

2. Diffuser width b3 $=6.8 \mathrm{~mm}$, the working fluid is "Air Ideal Gas", $\mathrm{P}_{\text {in }}=1 \mathrm{~atm}$, the stage was counted without seals;

3. Diffuser width b3 $=5.3 \mathrm{~mm}$, the working fluid is "Air Ideal Gas", $\mathrm{P}_{\text {in }}=1 \mathrm{~atm}$, the stage was counted with seals;

4. Diffuser width b3 $=6.8 \mathrm{~mm}$, the working fluid is "Air Ideal Gas", $\mathrm{P}_{\text {in }}=1 \mathrm{~atm}$, the stage was counted with seals;

5. Diffuser width b3 $=5.3 \mathrm{~mm}$, the working fluid is "Air Ideal Gas", $P_{\text {in }}=10 \mathrm{~atm}$, the stage was counted without seals;

6. Diffuser width b3 $=6.8 \mathrm{~mm}$, the working fluid is "Air Ideal Gas", $P_{\text {in }}=10$ atm, the stage was counted without seals;

7. Diffuser width $\mathrm{b} 3=5.3 \mathrm{~mm}$, the working fluid "Air Ideal Gas", $\mathrm{P}_{\text {in }}=10 \mathrm{~atm}$, stage was counted with seals;
8. Diffuser width b3 $=6.8 \mathrm{~mm}$, the working fluid is "Air Ideal Gas", $P_{\text {in }}=10$ atm, the stage was counted with seals;

9. Diffuser width $\mathrm{b} 3=5.3 \mathrm{~mm}$, the working fluid is "Air Ideal Gas", $P_{\text {in }}=10$ atm, the stage was counted without seals;

10. Diffuser width $\mathrm{b} 3=6.8 \mathrm{~mm}$, the working fluid is "Air Ideal Gas", $P_{\text {in }}=10$ atm, the stage was counted without seals;

11. Diffuser width b3 $=5.3 \mathrm{~mm}$, the working fluid is "Air Ideal Gas", $P_{\text {in }}=10$ atm, the stage was counted with seals;

12. Diffuser width $b 3=6.8 \mathrm{~mm}$, the working fluid is "Air Ideal Gas", $P_{\text {in }}=10$ atm, the stage was counted with seals.

Thus, based on the results of this work, it will be possible to conclude what effect the listed factors have on the stage characteristics and the flow structure in its elements, and also recommendations will be given on the problem formulation and carrying out calculations in simulating low-flow stages using computational fluid dynamics methods in calculating a viscid gas.

In the first phase, geometric models of the angular sectors of the flow path elements of the compressor stage were built. The model elements of the flow path were built using the commercial CAD package Pro / Engineer Wildfire 5.0 (inlet, vaneless diffuser, swinging elbow, outlet, seals) and the ANSYS Bladegen 14.0 application (impeller, return channel) included in the software package ANSYS Workbench 14.0. Copyright holder of software packages licenses - SPbSPU.

In the second phase of the work, computational grids were built for the corner sectors of the flow path elements using ICEM CFD (inlet elbow, vaneless diffuser, swinging elbow, outlet elbow, seals) and the TURBOGRID application (impeller, return channel) included in the ANSYS software package Workbench 14.0. All constructed meshes were of block-structured type.

Table 1 shows the number of mesh elements and the sector angle for each element of the flow path of the stage for the case taking into account the effect of seals and without seals.

Table 1. The number of the computational grid elements of the stage flow part.

\begin{tabular}{|c|c|c|}
\hline Flow path element & $\begin{array}{c}\text { Number of } \\
\text { grid elements }\end{array}$ & $\begin{array}{c}\text { Sector } \\
\text { angle }\end{array}$ \\
\hline Inlet elbow & 199.381 & $30^{0}$ \\
\hline Impeller & 662.887 & $24^{0}$ \\
\hline $\begin{array}{c}\text { Vaneless diffuser, swinging } \\
\text { elbow }\end{array}$ & 315.315 & $24^{0}$ \\
\hline Return channel & 1.119 .600 & $45^{0}$ \\
\hline Outlet elbow & 145.314 & $45^{0}$ \\
\hline Seal No.1 & 853.866 & $24^{0}$ \\
\hline Outlet elbow with seal No.2 & 1.091 .649 & $24^{0}$ \\
\hline $\begin{array}{c}\text { Compressor mesh without } \\
\text { seals }\end{array}$ & 2.442 .497 & \\
\hline Compressor mesh with seals & 4.242 .698 & \\
\hline
\end{tabular}

The constructed computational grids of the compressor flow path elements were combined in the 
CFX-Pre application (Ansys product) into a single computational compressor grid. The compressor mesh consists of 4.24 million elements for the case with the effect of seals and 2.44 million elements for the case without the effect of seals.

In the third phase, the boundary conditions were set for the compressor and the elements. The calculation was carried out with the SST turbulence model [18], adiabatic hydraulically smooth walls.

Figure 2 shows a unified computational grid of the compressor for the case that takes into account the effect of seals with specified boundary conditions.

In the near-wall areas, the mesh was refined in order to lower the average level of values and to model the boundary layer correctly. Figure 3 shows a typical case of near-wall thickening at the seal walls.

Calculations of the entire computational domain of the compressor were made on 4 cluster nodes, with 4 processor cores in each node. Calculations for each mode were made at 1000 iterations.

In the solver parameters, the Specified blend factor = 0.8 function was used to improve convergence.

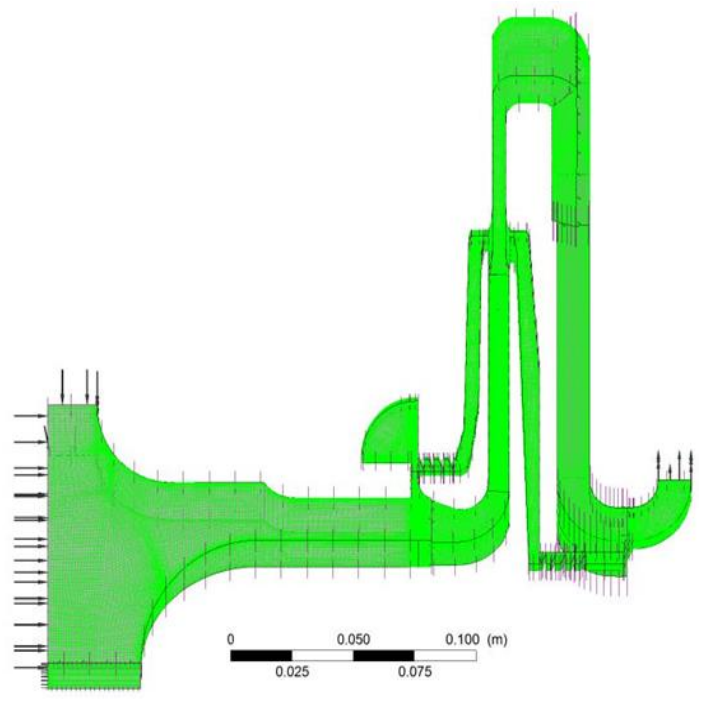

Fig. 2. Unified computational compressor grid with specified boundary conditions.

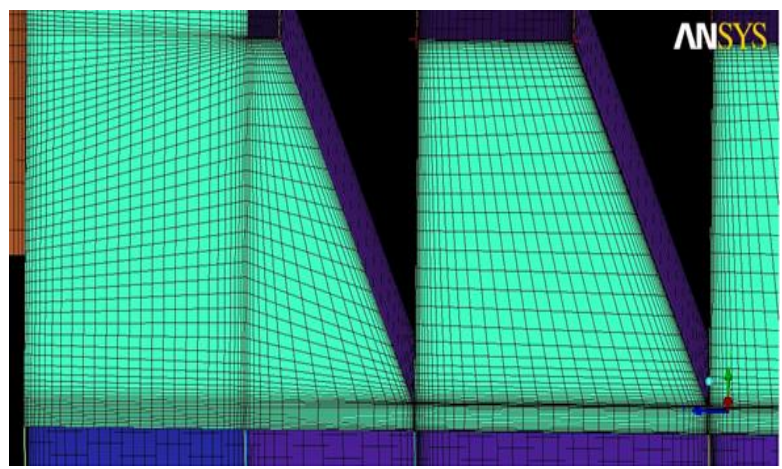

Fig. 3. Illustration of wall thickening at the walls of the seal wall.

12 series of calculations were carried out, 7 modes for each series. In total, 77 different modes were counted.

\section{Results}

In fig. 4, you can see the history of convergence for modes No. 4 (diffuser width $\mathrm{b} 3=6.8 \mathrm{~mm}$, working fluid "Air Ideal Gas", $\mathrm{P}_{\text {in }}=1 \mathrm{~atm}$, stage was considered with seals) and No. 8 (Diffuser width $\mathrm{b} 3=6.8 \mathrm{~mm}$, working fluid " Air Ideal Gas ", $\mathrm{P}_{\text {in }}=10$ atm, the stage was counted with seals). Both modes are close to the design mode, that is, the mode which has the maximum efficiency. The modes differ in inlet pressure. The convergence in both cases is good enough. But as can be seen from the figures, the case where the higher pressure has insignificant pulsations, and when solving the Navier-Stokes equations, the number of the root-meansquare " nonviscous" RMS reached the value $10^{-4}$, and in the case with $\mathrm{P}_{\text {in }}=1$ atm $10^{-5}$, which is much better, therefore the solution is more accurate.

RMS values exceeding $10^{-4}$ may be sufficient to obtain a qualitative flow picture. Although an RMS of $10^{-4}$ does not lead to complete convergence, this value of the standard deviation may be sufficient for a number of engineering problems.

The values $10^{-5}$ correspond to good convergence and are sufficient for most engineering problems. The exponents on the boundary $10^{-6}$ or lower correspond to very good convergence and may be required only for problems with complex geometry. In most cases, this level of convergence can be achieved only when calculating on a powerful cluster with high productivity.
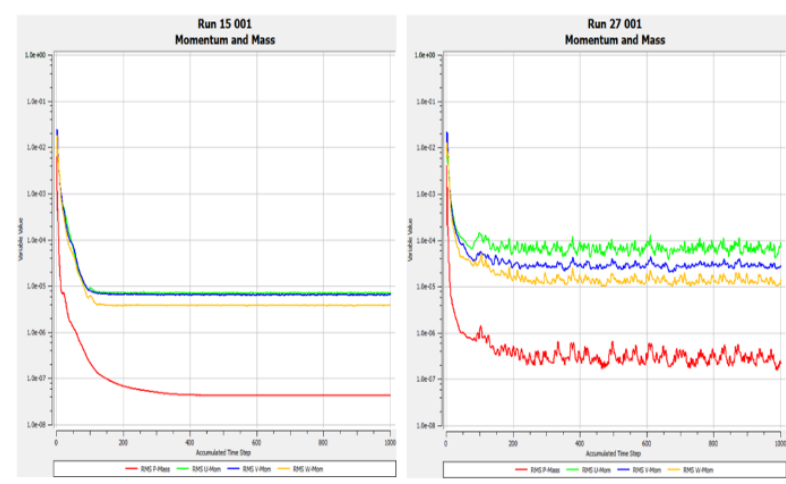

Fig. 4. History of convergence for modes No. 4 and No. 8 .

Below are the characteristics obtained as a result of a full-scale and numerical experiment for a series of calculations taking into account the effect of seals, the working fluid is nitrogen, $P_{\text {in }}=10$ atm. They show the dependences of the total $\mathrm{P} *$ and static pressure $\mathrm{P}$ on the conditional mass-flow coefficient $\Phi$ in sections $2-2,3-3$ and 0'-0 '(see sections in Fig. 1). 


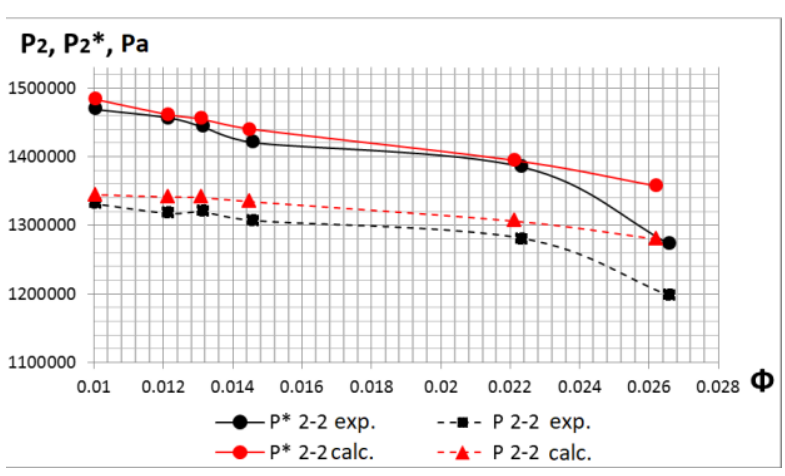

Fig. 5. Dependence of total $\left(\mathrm{P}^{*}\right)$ and static pressure $(\mathrm{P})$ on the conditional mass-flow coefficient $(\Phi)$ in section 2-2.
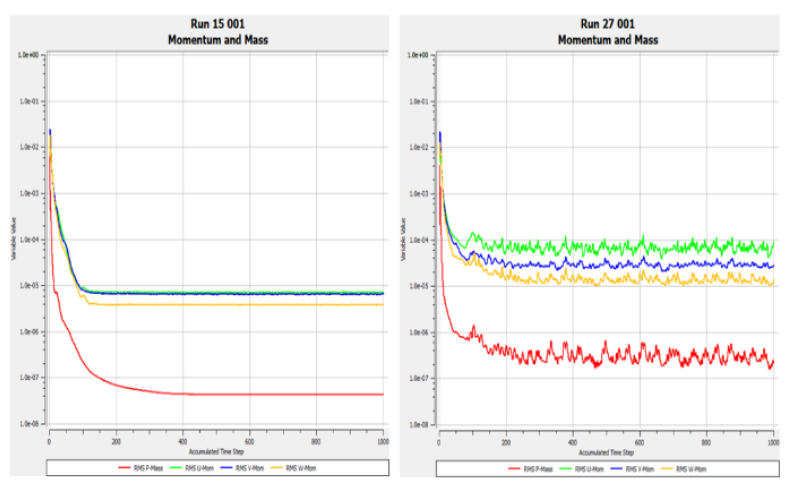

Fig. 6. Dependence of total $(\mathrm{P} *)$ and static pressure $(\mathrm{P})$ on the conditional mass-flow coefficient $(\Phi)$ in section 3-3.

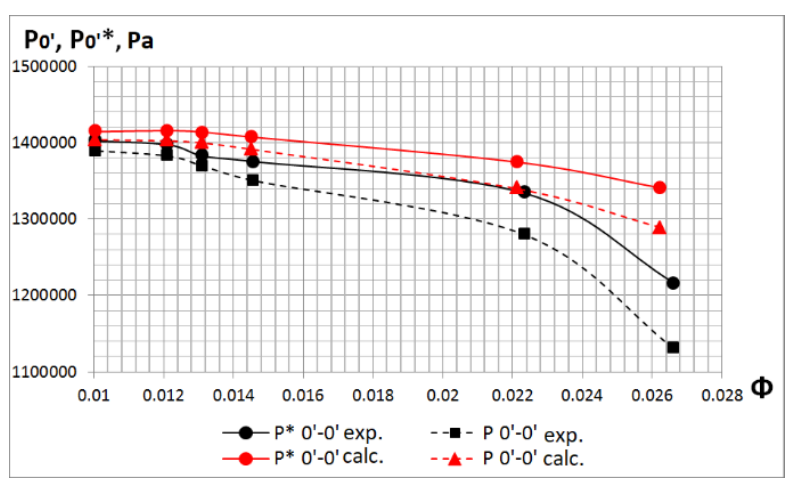

Fig. 7. Dependence of total $(\mathrm{P} *)$ and static pressure $(\mathrm{P})$ on the conditional mass-flow coefficient $(\Phi)$ in section 3-3.

As can be seen from the graphs, the calculated characteristic of the total and static pressure in sections 2-2 and 3-3 starting with $\Phi=0.022$ are very much in line with the experimental data. In the section $0^{\prime}-0^{\prime}$ can be seen a greater deviation of the calculated data from the experimental.

Table 2 shows the difference in absolute values of total and static pressure as a percentage of the experimental data values.
Table 2. Deviation of calculated and experimental characteristics for pressure values, $\%$.

\begin{tabular}{|c|c|c|c|c|c|c|c|}
\hline & & \multicolumn{6}{|c|}{$\begin{array}{c}\text { The conditional mass-flow coefficient } \\
\Phi\end{array}$} \\
\hline & Section & 0.0262 & 0.0221 & 0.0145 & 0.0131 & 0.0121 & 0.0101 \\
\hline \multirow{4}{*}{$\begin{array}{c}\text { At } \\
\text { total } \\
\text { pressu } \\
\text { re }\left(\mathbf{P}^{*}\right)\end{array}$} & $0-0$ & 0.46 & 0.41 & 0.13 & 0.30 & 0.45 & 0.48 \\
\hline & $2-2$ & 6.29 & 0.69 & 1.38 & 0.80 & 0.33 & 0.97 \\
\hline & $3-3$ & 6.56 & 1.48 & 1.35 & 1.17 & 0.59 & 0.42 \\
\hline & $0^{\prime}-0^{\prime}$ & 9.27 & 2.97 & 2.29 & 2.25 & 1.30 & 0.86 \\
\hline \multirow{4}{*}{$\begin{array}{c}\text { At } \\
\text { static } \\
\text { pressu } \\
\text { re }(\mathbf{P})\end{array}$} & $0-0$ & 0.47 & 0.25 & 0.00 & 0.07 & 0.21 & 0.22 \\
\hline & $2-2$ & 6.49 & 1.92 & 2.06 & 1.57 & 1.78 & 0.99 \\
\hline & $3-3$ & 6.78 & 2.61 & 1.76 & 1.34 & 1.62 & 0.75 \\
\hline & $0^{\prime}-0^{\prime}$ & 12.29 & 4.51 & 2.96 & 2.19 & 1.40 & 1.03 \\
\hline
\end{tabular}

As can be seen from the graphs in Fig. 5, 6, 7 and Table 2, on modes close to the calculated ones, the error is within $3 \%$, which can be considered a very good result that satisfies the accuracy of engineering calculations in the design of flow paths and does not go beyond the permissible error during the experiment.

Calculation time for one mode, excluding seals: 1011 hours, for mode, taking into account seals: 17-18 hours with full use of 4 cluster nodes. Thus, to obtain one characteristic consisting of 7 modes, 70-77 hours of machine time were spent for modes without compaction and 119-126 for modes with compaction, respectively. The total machine time spent to obtain 12 characteristics with 7 modes in each is approximately equal to 1176 hours.

Fig. 8 shows the total pressure contour in the meridian plane. The nature of the pressure distribution is reliable.

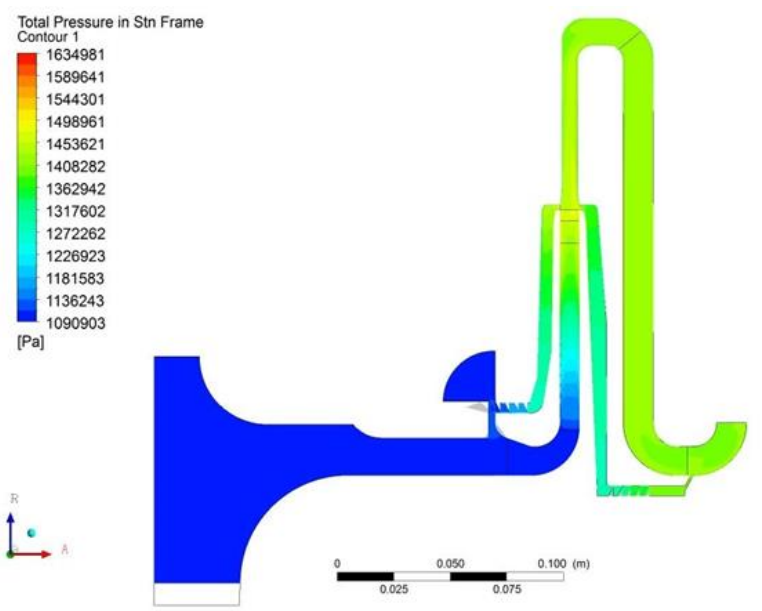

Fig. 8. Contours of total pressure isobars in the meridian plane.

Figure 9 shows the static pressure contour in labyrinth seal No.1, and fig. 10 shows isotachs of flow rates in labyrinth seal No.1. These figures are interesting in that we can observe the labyrinth seal operation. Seals are necessary to minimize gas overflow from the cavities of the flow path with high pressure to the cavity with lower pressure. The labyrinth seal is a system of thin ridges with sharp edges that fit the minimum distance to the sealing surface.

Contact seals are unsuitable for mechanical reasons due to the high peripheral speed of the sealing rotor elements; therefore, contactless labyrinth seals are used. 


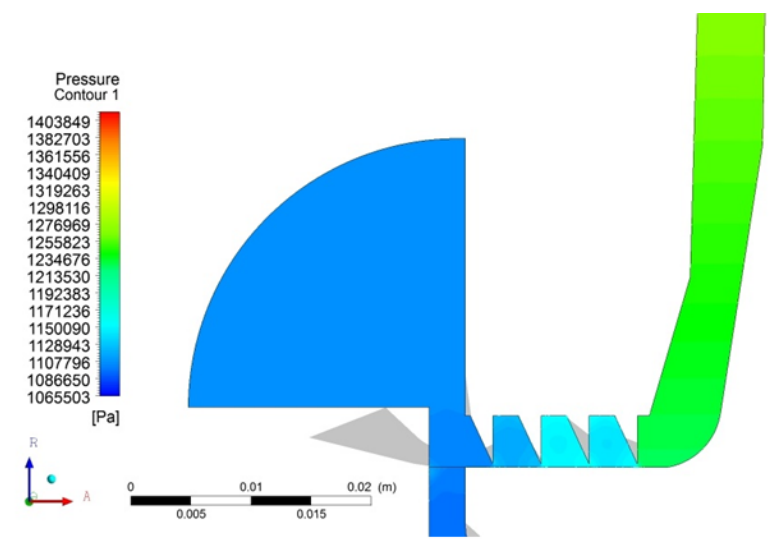

Fig. 9. Static pressure isobar contours in labyrinth seal No. 1 on the impeller shroud.

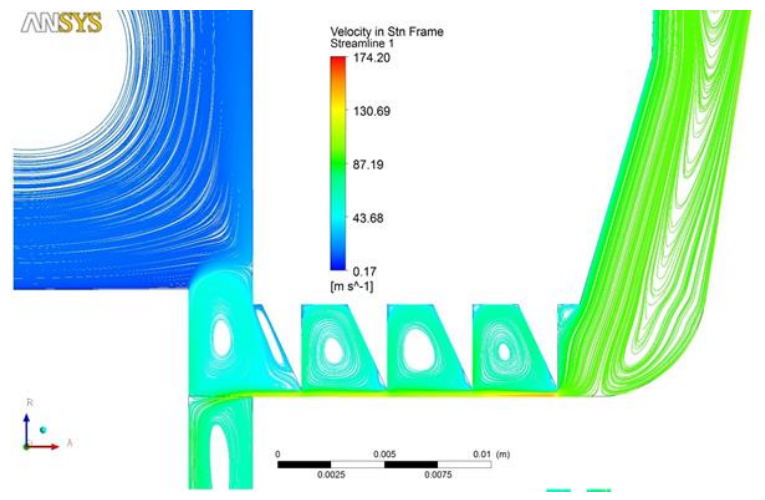

Fig. 10. Isotachs of velocities and flow streamlines in the labyrinth seal No. 1 on the impeller shroud.

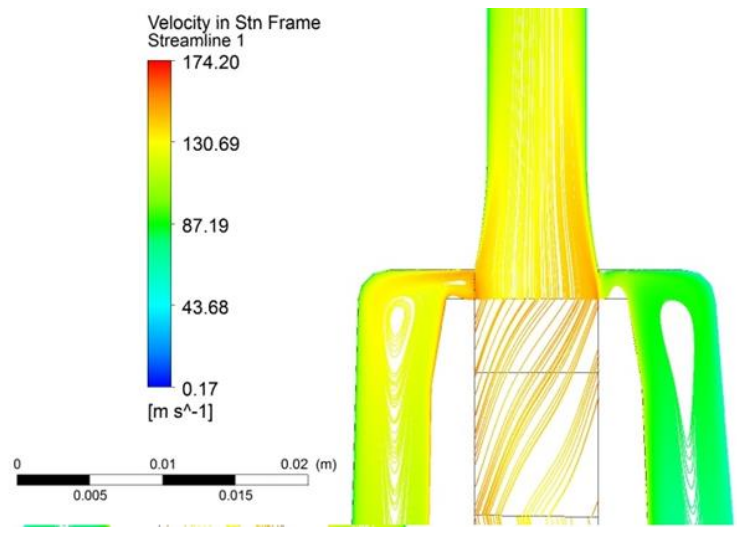

Fig. 11. Isotachs of velocities and flow streamlines at the junction of the impeller, vaneless diffuser and labyrinth seals No.1 (left) and No.2 (right) on the impeller shroud.

In fig. 11 can be observed the isotachs of the flow rates at the junction of the impeller, the vaneless diffuser and labyrinth seals No.1 and No.2 on the impeller shroud.

\section{Discussions}

1. For low-flow stages of centrifugal compressors in modeling a working process using computational fluid dynamics methods, taking into account the availability of labyrinth seals and gaps between the hub and shroud in the flow path has a significant effect on the characteristics of the stage and brings their values closer to the data of a full-scale experiment.

2.Setting up a numerical experiment using a labyrinth packing in the computational model increases the complexity of constructing computational grids, increases the cells number of computational grid, computation time and requirements for computational resources.

3. The characteristics, where the working fluid the real gas nitrogen "N2" was used, at modes close to the calculated ones are almost equal to the characteristics where the working fluid "Air Ideal Gas" was used, under equal conditions.

4. The calculated characteristics are "above" the experimental dependence, i.e. the considered dimensionless quantities are overestimated in the numerical experiment relative to the full-scale one. Perhaps this is due to the fact that when formulating the problem, a hydraulically smooth wall was used, without taking into account the roughness. It is necessary to carry out a series of numerical experiments taking into account the roughness.

5. In general, the applied problem statement provides satisfactory accuracy for solving design and optimization problems. It is necessary to take into account the "difference of large numbers", i.e. when relatively small errors in absolute values cause rather high errors in relative values.

Visualization gives a reasonably reliable picture of the flow.

\section{References}

1. L.Ya. Strizhak, N.I. Sadovsky, I.P. Suslina, Investigation of low-flow centrifugal stages on a closed circuit stand, 13.4, 254, (2010)

2. L.Ya. Strizhak, I.P. Suslina, Investigation of vaneless diffusers, 9, 149, (2010)

3. A.V. Korshunov, L. Ya. Strizhak, Analysis of the impact of the geometric characteristics of the return channel on its efficiency, 13.6, 278, (2010)

4. Boldyrev, Y., Rubtsov, A., Kozhukhov, Y., Lebedev, A., Cheglakov, I., Danilishin, A. Simulation of unsteady processes in turbomachines based on nonlinear harmonic NLH-method with the use of supercomputers. CEUR Workshop Proceedings, 1482, Pages 273-279. 1st Russian Conference on Supercomputing Days 2015, RuSCDays 2015; Moscow; Russian Federation; 28 September 2015, 29 September 2015 (2015)

5. V.V. Neverov, Y.V. Kozhukhov, A.M. Yablokov, A.M., Lebedev, A.A. The experience in application of methods of computational fluid dynamics in correction of the designed flow path of a two-stage compressor, AIP Conference Proceedings, 2007, 30048 (2018). DOI: 10.1063/1.5051909

6. P. Le Sausse, P. Fabrie, D. Arnou D, F. Clunet, CFD comparison with centrifugal compressor measurements on a wide operating range, EPJ Web of Conferences, 45, 01059 (2013) 
7. E. Sundström, B. Kerres, S. Sanz, M. Mihăescu, On the Assessment of Centrifugal Compressor Performance Parameters by Theoretical and Computational Models. Volume 2C: Turbomachinery (2017). doi:10.1115/gt2017-65230

8. A. Aksenov, Y. Kozhukhov, M. Sokolov, A. Simonov, Analysis and modernization of real gas thermodynamic calculation for turbocompressors and detander units, MATEC Web of Conferences, 245, (2018),

DOI: $10.1051 /$ matecconf/201824509005

9. Juan Sebastian Lopez-Echeverrya, Simon ReifAchermana, Eduard Araujo-Lopez. Peng-Robinson equation of state: 40 years through cubics. Fluid Phase Equilibria (2017).

10. K.H. Lüdtke, Process centrifugal compressors: basics, function, operation, design, application, (Springer Science \& Business Media, 2004).

11. V.M. Ivanov, Y.V. Kozhukhov, A.M. Danilishin, Calculation of the impellers head characteristics of the low-flow centrifugal compressor stages based on quasi-three-dimensional inviscid and viscous methods, AIP Conference Proceedings, 2141, 30064 (2019). DOI:10.1063/1.5122114.

12. A. Yablokov, I. Yanin, N. Sadovskyi, Y. Kozhukhov, M.H. Nguyen, Numerical characteristics of a centrifugal compressor with a low flow coefficient, E3S Web of Conferences, 140, № 6010 (2019).

DOI:10.1051/e3sconf/201914006010

13. V. Ivanov, Y. Kozhukhov, M.H. Nguyen, Head Math Model for the Low-Flow Impellers of the Centrifugal Compressors, E3S Web of Conferences, 140, 6008 (2019). DOI:

10.1051/e3sconf/201914006008

14. Kiryll Kabalyk, Władysław Kryłłowicz. Numerical modeling of the performance of a centrifugal compressor impeller with low inlet flow coefficient. ISSN 0079-3205 Transactions IFFM 131, 97-109 (2016)

15. G. Xi, Z. Wang, X. Li, S. Wang, Aerodynamic Design and Experimental Validation of Centrifugal Compressor Impellers With Small Flow Rate. Volume 7: Turbomachinery, Parts A and B (2009). doi:10.1115/gt2009-59785

16. Yongsheng Wang, Feng Lin, Chaoqun Nie, Abraham Engeda. Design and Performance Evaluation of a Very Low Flow Coefficient Centrifugal Compressor. International Journal of Rotating Machinery, 2013, Article ID 293486, 12 pages, 2013. https://doi.org/10.1155/2013/293486

17. N.I. Sadovsky, Increasing the efficiency of low-flow stages of high and ultra-high pressure centrifugal compressors based on the study of the influence of the Reynolds number and roughness on working processes, $\mathrm{PhD}$ thesis (1994)

18. D.M. Hamburger, Numerical modeling of viscous gas flow in a centrifugal compressor stage: methodology and results, PhD thesis (2009). 